\title{
Peripherally Inserted Central Catheters (PICC): A Promising Technique
}

\author{
Vidal V, Muller C, Soussan J
}

Service de radiologie - Hopital de la Timone, 264 rue Saint Pierre, 13385 Marseille Cedex 05

\begin{abstract}
Peripherally Inserted Central Catheters (PICC): a promising technique. To describe technical features and benefits from PICC lines.
\end{abstract}

Keywords: Catheters, Central venous access, Interventional Radiology

A stable and sustainable venous access is essential for any inpatient in need for a parenteral treatment (antibiotic therapy, nutrition, chemotherapy etc). The use of a peripheral venous line, notably in the case of poor venous capital, is not always possible to implement such treatments. The usual alternative consists in the placement of a conventional central venous access. In the last decade, a new venous access technique has been developed in North America: Peripheral Inserted Central Catheter or PICC. It consists in the insertion of a catheter in a deep vein of the arm under ultrasound guiding. The distal tip of the catheter is then placed in the superior vena cava. Its usage is the same as that of a conventional central access but this catheter offers major advantages. The placement technique is simple, painless, non traumatic and with very little iatrogenic risk. This venous access can be maintained for several months and used for home medical care. Finally, the catheter inserted in the patient's arm doesn't hinder the patient's everyday activities. The aim of this note is to act as a reminder of the insertion technique for these PICCs which complications are rare, as reported recently.

A PICC is a soft and flexible silicon or polyurethane catheter (fig.1a). It is connected to thicker and reinforced tubing that remains outside the vein. It can be single or double lumen and equipped with a distal anti reflux valve to avoid blood clots within the catheter. Available diameters range from 4 to 7 French's and lengths from 50 to $60 \mathrm{~cm}$.

After an extensive asepsis and the application of a tourniquet high on the upper arm, a fenestrated sterile drape is placed just above the anterior cubital region with the arm supine. The radiologist locates the basilic, humeral and cephalic venous networks using the ultrasound probe of which is protected by a sterile cover. Phlebographic locating after injection of a contrast media through hand venepuncture is not necessary. Ideally, the radiologist punctures the basilic vein because of its high lumen. The puncture of the humeral vein is more awkward considering the proximity of the humeral artery and of the median nerve. The cephalic vein must be chosen as a last resort as the arch can be difficult to catheterize. In all cases, the vein shall be punctured above the elbow as to not hinder the everyday flexion movements. After local anesthetic, the vein is punctured with a 21 gauge needle (fig.1b) under ultrasound locating and the vein is catheterized with a 0.018 inches metal guide wire (fig. 1c) up to

Correspondence to: Vincent VIDAL, Service de radiologie, Hospital de la Timone, 264 rue Saint Pierre, 13385 Marseille Cedex 05.

Email: vincent.vidal@ap-hm.fr 


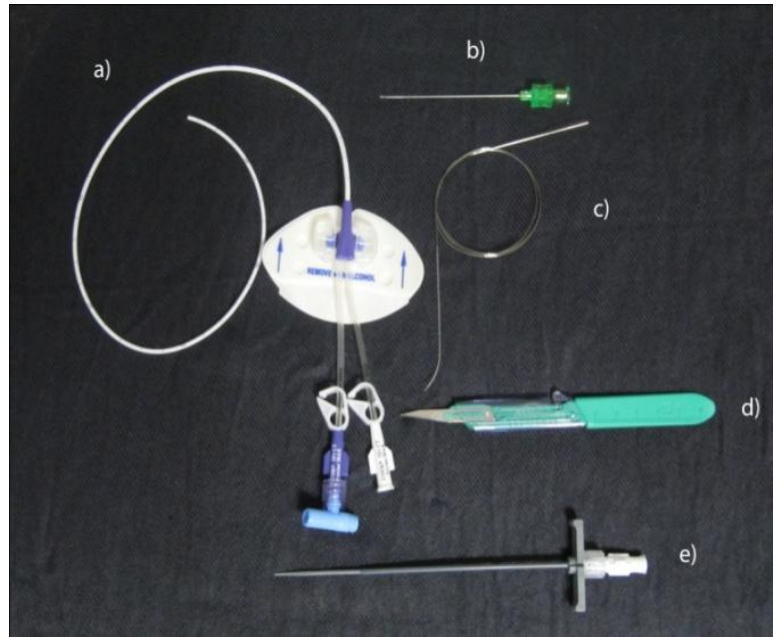

Fig. 1: Material: catheter (a), needle (b), guide wire (c), blade (d) \& peel-away (e)

the superior vena cava under fluoroscopic locating. After a discrete incision with a number 11 scalpel blade (fig. 1d), a peelaway sheath is inserted onto the guide wire. The distal tip of the guide wire is placed at the terminal part of the superior vena cava to determine the appropriate length of the PICC (from the skin to the superior vena cava terminal). The guide wire is clamped at the skin orifice and then withdrawn. Once measured, this segment of the guide is used as a reference for the length of the PICC, the tip of which can accordingly be cut with the scalpel blade. The PICC is then inserted in the peel-away sheath and moved up to the superior vena cava. The peel-away sheath is withdrawn and the PICC is fixed to the skin either by suture or by adhesive dressing (fig. 2). Suture is recommended when the patient is agitated or dement as it offers optimal fixation. In other cases, adhesive dressing is better tolerated as it doesn't entail any septic risk. The catheter is then flushed with saline and protected with dressings. An X-ray image is taken at the end of the procedure to show the right positioning of the catheter in the superior vena cava. In normal conditions, this placement should take 15 to 20 minutes.

PICCs enable to supply a wide variety of therapies through the central venous access (antibiotic therapy, chemotherapy, parenteral nutrition). They are more and more widely used since numerous studies have shown their efficacy and innocuousness. Main indications are parenteral treatments which duration exceeds one week and nutrition for patients with a poor venous capital. They are also very useful during chemotherapies when an implantable site (port) is unusable (site infection, patient's refusal) or in the case of very short chemotherapies. Finally the presence of a stable and effective venous access avoids doing multiple and traumatic venous punctures during long term hospitalizations, notably for elderly subjects. There is no specific contraindication to this type of material, except for the usual contraindications to venous punctures in the upper limb (previous history of axillary nodes dissection). A new generation of PICCs with a reinforced structure allows iodinated contrast boluses possible with a

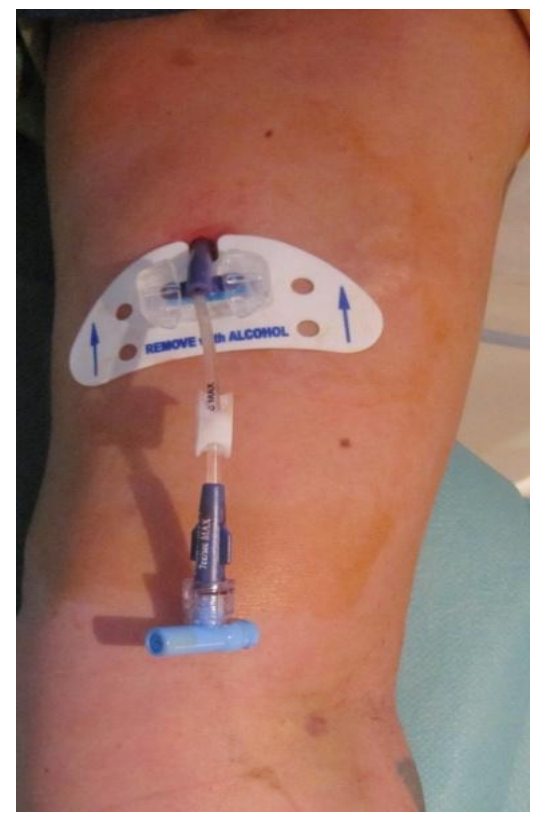

Fig. 2: PICC inserted in the right brachial vein.

flow rate of 2 to $3 \mathrm{ml} / \mathrm{sec}$. One of the major advantages of PICCs lies in the fact that the patient can go home while keeping this central venous access in place, thus enabling the implementation of sophisticated ambulatory treatments and reducing the cost of hospital stays. The maintenance of the catheter is simple but must be thorough to avoid the development of complications such 
as infections and thrombosis of the catheter. It consists in a daily rinsing under strict asepsis by the use of a saline solution when the catheter isn't in use. The PICC can remain in place for up to 6 months and its withdrawal is done by simple traction of the catheter followed by a gentle hand compression of the puncture area. The overall rate of complication is inferior to that of a conventional central access and the minor complications that have been reported are catheter infections ( 1 to $2 \%$ ), peripheral venous thrombosis (3 to 5\%), catheter fractures (less than $0.01 \%)$, arrhythmias $(0.2$ to $0.4 \%$ ), haematoma of the puncture area $(1 \%)$. These various minor complications can easily be prevented or treated. ${ }^{1-6}$ Compared to the other central vascular access systems, the rate of infectious complications of the

\section{References}

1. Vidal V, Muller C, Jacquier A, et al. Évaluation prospective des complications des PICCs. J Radiol 2008;89:495-8.

2. Mermel LA, Farr BM, Sherertz RJ et al. Guidelines for management of intravascular catheter-related infections. Clin Infect Dis 2001;32:1249-72.

3. Grove JR, Pevec WC. Venous thrombosis related to peripherally inserted central catheters. J Vasc Interv Radiol 2000;11:837-40.

4. Allen AW, Megargell JL, Brown DB, et al. Venous thrombosis associated with the placement of peripherally inserted central catheters. J Vasc Interv Radiol 2000;11:1309-14.

5. Chow LM, Friedman JN, Macarthur C, et al. Peripherally inserted central catheter (PICC) fracture and embolization in pediatric population. $\mathbf{J}$ bacteremia type is roughly the same as that of conventional central venous accesses $(2 \%)$ and lowers than that of port-a-cath $(3.6 \%))^{7.8}$ The level of satisfaction for patients who have benefited from this type of catheter is very encouraging $(90 \%$ of the patients are satisfied when the catheter is inserted above the elbow). ${ }^{9}$ Indeed, in this position, the catheter doesn't hinder the patient's everyday movements especially when it is inserted in the non-dominant arm.

In the future, as they are already now in North America and some European countries, PICCs should become a significant daily activity for interventional radiology centers, with the aim of improving patient's wellbeing and nursing care as well as promoting ambulatory treatments.

\section{Pediatr 2003;142; 141-4.}

6. Chrisman HB, Omary RA, Nemcek AA, et al. Peripherally inserted central catheters: guidance with use of US versus venography in 2650 patients. J Vasc Interv Radiol 1999;10:473-5.

7. Maki DD, Kluger DM, Crnich CJ. The risk of bloodstream infection in adults with different intravascular devices: a systematic review of 200 published prospective studies. Mayo Clin Proc 2006;81:1159-71.

8. Safdar N, Maki DG. Risk of catheterrelated bloodstream infection with peripherally inserted central venous catheters used in hospitalized patients. Chest 2005;128:489-95.

9. Polak JF, Anderson D, Hagspiel K et al. Peripherally inserted central venous catheters: factors affecting patient satisfaction. AJR Am J Roentgenol 1998;70:1609-11. 